\title{
Correction to: Clinical features and treatment efficacy for IgG4-related thyroiditis
}

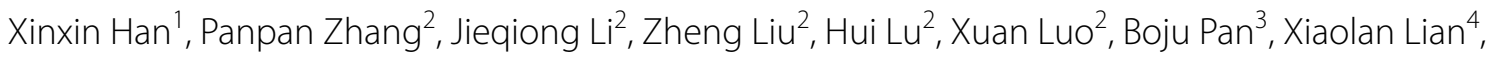 \\ Xuejun Zeng ${ }^{1^{*}}$, Wen Zhang ${ }^{2^{*}}$ and Xiaofeng Zeng ${ }^{2}$
}

\section{Correction to: Orphanet J Rare Dis (2021) 16:324 https://doi.org/10.1186/s13023-021-01942-x \\ It was highlighted that in the original article [1] the Funding section was incomplete. This Correction article shows the complete Funding section. The original article has been updated.}

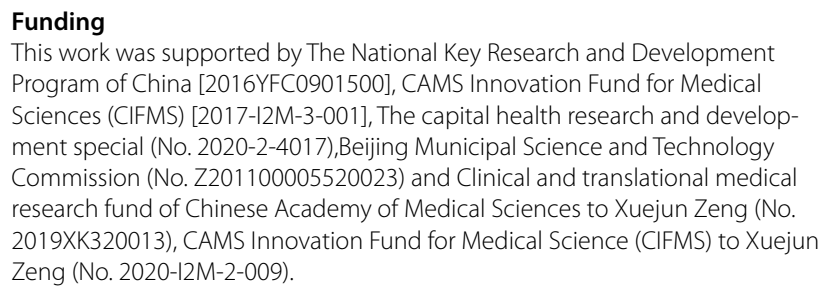

\section{Author details}

'Department of General Practice, Peking Union Medical College Hospital, Chinese Academy of Medical Science and Peking Union Medical College, State Key Laboratory of Complex Severe and Rare Diseases, Beijing, People's Republic of China. ${ }^{2}$ Department of Rheumatology, Peking Union Medical College Hospital, Chinese Academy of Medical Science and Peking Union Medical
College, Key Laboratory of Rheumatology and Clinical Immunology, State Key Laboratory of Complex Severe and Rare Diseases, Ministry of Education and National Clinical Research Center for Dermatologic and Immunologic Diseases (NCRC-DID), No.1 Shuai Fu Yuan, Dong Cheng District, Beijing 100730 People's Republic of China. ${ }^{3}$ Department of Pathology, Peking Union Medical College Hospital, Chinese Academy of Medical Science and Peking Union Medical College, State Key Laboratory of Complex Severe and Rare Diseases, Beijing, People's Republic of China. ${ }^{4}$ Department of Endocrine, Peking Union Medical College Hospital, Chinese Academy of Medical Science and Peking Union Medical College, State Key Laboratory of Complex Severe and Rare Diseases, Beijing, People's Republic of China.

Published online: 01 November 2021

\section{Reference}

1. Han, et al. Clinical features and treatment efcacy for lgG4-related thyroiditis. Orphanet J Rare Dis. 2021;16:324. https://doi.org/10.1186/ s13023-021-01942-X.

\section{Publisher's Note}

Springer Nature remains neutral with regard to jurisdictional claims in published maps and institutional affiliations.

The original article can be found online at https://doi.org/10.1186/s13023021-01942-x

*Correspondence: zxjpumch@126.com; zhangwen91@sina.com

${ }^{1}$ Department of General Practice, Peking Union Medical College Hospital, Chinese Academy of Medical Science and Peking Union Medical College, State Key Laboratory of Complex Severe and Rare Diseases, Beijing, People's Republic of China

${ }^{2}$ Department of Rheumatology, Peking Union Medical College Hospital, Chinese Academy of Medical Science and Peking Union Medical College, Key Laboratory of Rheumatology and Clinical Immunology, State Key Laboratory of Complex Severe and Rare Diseases, Ministry of Education and National Clinical Research Center for Dermatologic and Immunologic Diseases (NCRC-DID), No.1 Shuai Fu Yuan, Dong Cheng District, Beijing 100730, People's Republic of China

Full list of author information is available at the end of the article permits use, sharing, adaptation, distribution and reproduction in any medium or format, as long as you give appropriate credit to the original author(s) and the source, provide a link to the Creative Commons licence, and indicate if changes were made. The images or other third party material in this article are included in the article's Creative Commons licence, unless indicated otherwise in a credit line to the material. If material is not included in the article's Creative Commons licence and your intended use is not permitted by statutory regulation or exceeds the permitted use, you will need to obtain permission directly from the copyright holder. To view a copy of this licence, visit http://creativecommons.org/licenses/by/4.0/. The Creative Commons Public Domain Dedication waiver (http://creativecommons.org/publicdomain/zero/1.0/) applies to the data made available in this article, unless otherwise stated in a credit line to the data. 